\title{
Edentulism and Obstructive Sleep Apnea: A Case Report
}

\author{
Domenico Ciavarella ${ }^{1}$, Laura Guida ${ }^{1}$, Giovanni Battista ${ }^{1}$, Mario Dioguardi ${ }^{1}$, Roberto Sabato ${ }^{2}$, \\ Maria Pia Foschino Barbaro ${ }^{2}$, Donato Lacedonia ${ }^{2}$, Claudio Chimenti ${ }^{3}$, Letizia Perillo ${ }^{4}$, \\ Mario Mastrovincenzo 5 and Lorenzo Lo Muzio ${ }^{*}, 1$
}

\author{
${ }^{I}$ Department of Surgical Sciences, Faculty of Medicine, School of Dentistry, University of Foggia, Italy \\ ${ }^{2}$ Institute of Respiratory Disease, Department of Medical and Occupational Sciences, University of Foggia, Italy \\ ${ }^{3}$ Department of Surgical Sciences, Faculty of Medicine, School of Dentistry, University of L' Aquila, Italy \\ ${ }^{4}$ Department of Orthodontics, 2nd University of Naples, Naples, Italy \\ ${ }^{5}$ Department of Oral Sciences, Faculty of Medicine, School of Dentistry, Polytechnic University of Marche, Italy
}

\begin{abstract}
Purpose: Obstructive sleep apnea (OSA) is a common disease that is estimated to affect $2 \%$ of middle-aged women and $4 \%$ of middle-aged men. Reported risk factors include obesity, increased neck circumference, male sex and anatomical abnormalities of the face. Although edentulism is reported to change the anatomy and also impair the function of the upper airway, it has not been typically recognized as a risk factor for sleep-related breathing disorders.

Methods: The subject of this report is a 55 years old man with a body mass index (BMI) of $33 \mathrm{~kg} / \mathrm{m}^{2}$. Cephalometric assessments of head radiographs taken in the lateral plane with and without dentures were performed; mandible planehyoid (MP-H) distance and the posterior airway space (PAS) were measured. Oxygen saturation $\left(\mathrm{SaO}_{2}\right)$ and apnea/hypopnea index (AHI) were evaluated.

Results: A comparison of the polysomnographies taken with and without wearing the dentures during the night showed that $\mathrm{AHI}$ was reduced (from $20.0 / \mathrm{h}$ to $5.7 / \mathrm{h}$ ) and mean $\mathrm{SaO}_{2}$ increased (from $94.0 \%$ to $96.0 \%$ ). Cephalometric analysis showed that the removal of dentures led to a striking increase in the anteroposterior oropharyngeal wall distance from 5 $\mathrm{mm}$ to $10 \mathrm{~mm}$, while the mandible plane-hyoid distance does not change.

Conclusions: These findings were consistent with the hypothesis that edentulism not always worse OSA by an oropharyngeal collapse. Given the common occurrence of both conditions among the elderly, such as the reduction of obstructive sleep apneas with or without dentures, the observed relationship requires further investigations on the mechanisms through which the loss of teeth could help upper airway collapse during the night. In the present paper a case of reduction of OSA without dentures during sleep is shown.
\end{abstract}

Keywords: Obstructive sleep apnea, edentulism, dentures, risk factors.

\section{INTRODUCTION}

Obstructive sleep apnea (OSA) is a common disease that is estimated to affect $2 \%$ of middle-aged women and $4 \%$ of middle-aged men [1].

It is characterized by repetitive episodes of complete (apnea) or partial (hypopnea) upper airway obstruction occurring during sleep [2]. Whereas apnea is complete cessation of airflow, hypopnea is characterized by a $70 \%$ reduction of airflow for $\geq 10$ seconds or any reduction in airflow that is associated with either an arousal from sleep or $a \geq 3 \%$ arterial oxygen desaturation. Apneas and hypopneas as a result of these varying degrees and locations of upper airway obstructions are regarded as the most common sleeprelated breathing disorders (SRBD) [3].

*Address correspondence to this author at the Department of Surgical Sciences, Faculty of Medicine, School of Dentistry, University of Foggia, Via Rovelli 28, 71121 Foggia, Italy; Tel: 390881588080 ;

Fax: 390881588081; E-mail: 1lomuzio@tin.it
As measured by pulse oximetry, associated with these episodes is reduced blood oxygen saturation in spite of inspiratory efforts. Also associated is sleep fragmentation or disruption of the quality and duration of sleep along with the possible subjective reports of excessive daytime sleepiness and/or insomnia because of the repetitive arousals or awakenings that occur in an effort to establish airway patency, performance and cognitive decrements and cardiovascular dysfunction.

In order for a diagnosis of OSA to be made, a sleep study must demonstrate a minimum of five or more apneic or hypopneic episodes per each hour of sleep or 30 episodes per 6 hours of sleep [4].

Although obstruction of the upper airway may include multiple anatomical sites, closure of the upper airway is most commonly located in the retropalatal and retroglossal areas [5-7]. 
Reported risk factors include obesity, increased neck circumference, male sex and anatomical abnormalities of the face [1, 8-14].

Although edentulism is reported to change the anatomy and also impair the function of the upper airway $[15,16]$, so that many dentists recommend to not remove the denture during the night, it has not been typically recognized as a risk factor for sleep-related breathing disorders.

In fact, the results of this case report showed the advantage on removal of denture during the night in a patient with obstructive sleep apnea (OSA). This suggests that not always dentures wearing induces modifications in the position of the tongue, of the jaw and of the pharyngeal airway space that promote the reduction of apnea and hypopnea episodes.

\section{MATERIALS AND METHODS}

The subject of this report is a 55 years old man with a body mass index (BMI) of $33 \mathrm{~kg} / \mathrm{m}^{2}$.

His medical history suggests an increased risk for sleeprelated breathing disorders (SRBD). In fact, he is a former smoker of 40 cigarettes per day (he stopped smoking only a year ago), in drug treatment for hypertension and type 2 diabetes and also suffering from ischemic heart disease, treated with percutaneous transluminal coronary angioplasty (PTCA). Since 1994, he has been diagnosed with chronic obstructive lung disease (BPCO). As he began to experience daytime sleepiness, snoring and waking up at night because of urinary frequency, he also was reported to be suffering from obstructive sleep apnea syndrome (OSAS). In November 2010, he was referred to the "D'Avanzo" respiratory clinic because of the worsening of the abovementioned symptoms. Here, the patient received a complete overnight polysomnography (PSG), which is considered to be the "gold standard" in sleep medicine [17]. The physiologic parameters measured during a PSG include simultaneous and continuous monitoring of at least brain wave activity, eye movements, muscle activity of the legs and mandible, body position, heart rate and rhythm, blood pressure, snoring and respiratory activity that includes breathing patterns and oxygen saturation. He also completed the Epworth Sleepiness Scale (ESS), a test to identify degrees of sleepiness [18], with a score of 12. Investigations have shown that a score of 10 or 11 is considered to be the upper parameter for normal $[19,20]$. After these studies, the patient was discharged with a diagnosis of moderate OSAS $(\mathrm{AHI}=20 / \mathrm{h})$ and a request of an oral evaluation.

So, the patient's visit at School of Dentistry, University of Foggia, was the additional step taken to further evaluate this case. Many intra- and extraoral conditions have an association with risk for SRBD that warrant in-depth consideration. The patient showed a micro-uvula, a flat palate, a tonsils score of I (the standard grading system for the tonsils rates them on a scale from 0 to IV, with 0 indicating that the tonsils are absent and grade IV indicating they are grossly enlarged [21]) and a large tongue with a Mallampati score of III (the Mallampati score assesses tongue position relative to the soft palate as well as visualization of the oropharynx as indicators of the risk for
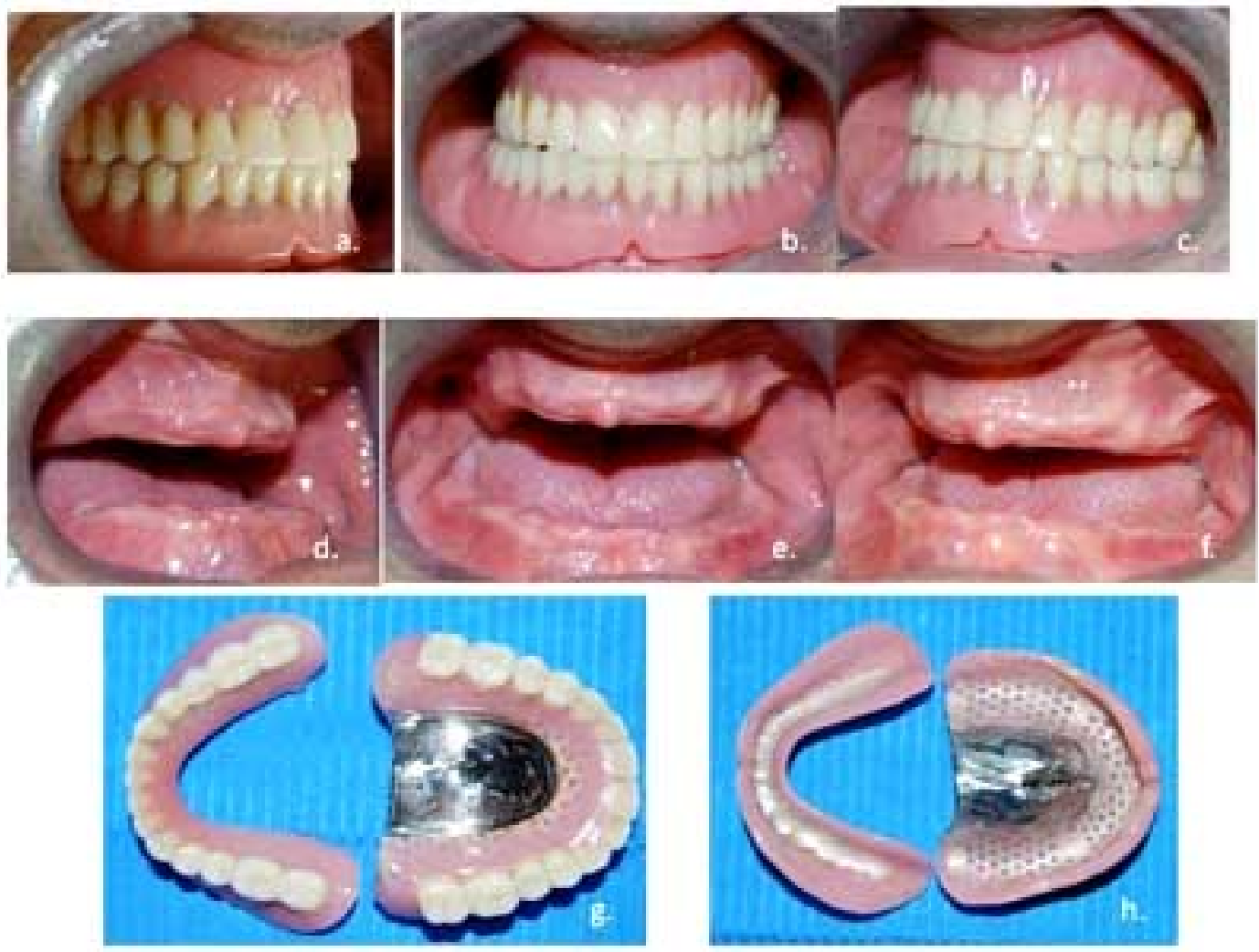

Fig. (1). (a) patient with dentures in right lateral view; (b) patient with dentures in frontal view; (c) patient with dentures in left view; (d) patient without dentures in right lateral view; (e) patient without dentures in frontal view; (f) patient without dentures in left lateral view; (g) dentures viewed from below; (h) dentures viewed from above. 
OSA. As the degree of obstruction of the oropharyngeal airway and the soft palate increases, the risk for OSA also increases. It has recently been demonstrated that as the score progresses from I to IV, the potential severity of OSA also worsens [22]. The patient's current dental health status, which includes the teeth as well as the supporting structures, was recorded: he is edentulous and was wearing new mobile upper and lower dentures for about two months (Fig. 1). Cephalometric assessments of the radiographs taken in the lateral plane with and without dentures were performed (Fig. 2). Cephalometric landmarks are shown in Table 1. The parameters evaluated were: the middle, the posterior and the inferior pharyngeal airway space (i.e. PAS, MAS and IAS), such as the distance between the posterior pharyngeal wall and the anterior soft tissue structures (lingual base, soft palate or uvula), the distance between the hyoid bone and the mandibular plane (MP-H), the distance of Hyoid $(\mathrm{H})$ to retrognation (RGN), the distance of base of epiglottis (Eb) to tongue tip (TT) and the tongue height (TGH). Finally, it was also requested a polysomnographic study without wearing dentures during the night to compare $\mathrm{AHI}$ and mean $\mathrm{SaO}_{2}$ with those obtained with dentures.

\section{RESULTS}

The patient's findings are shown in Table 2.

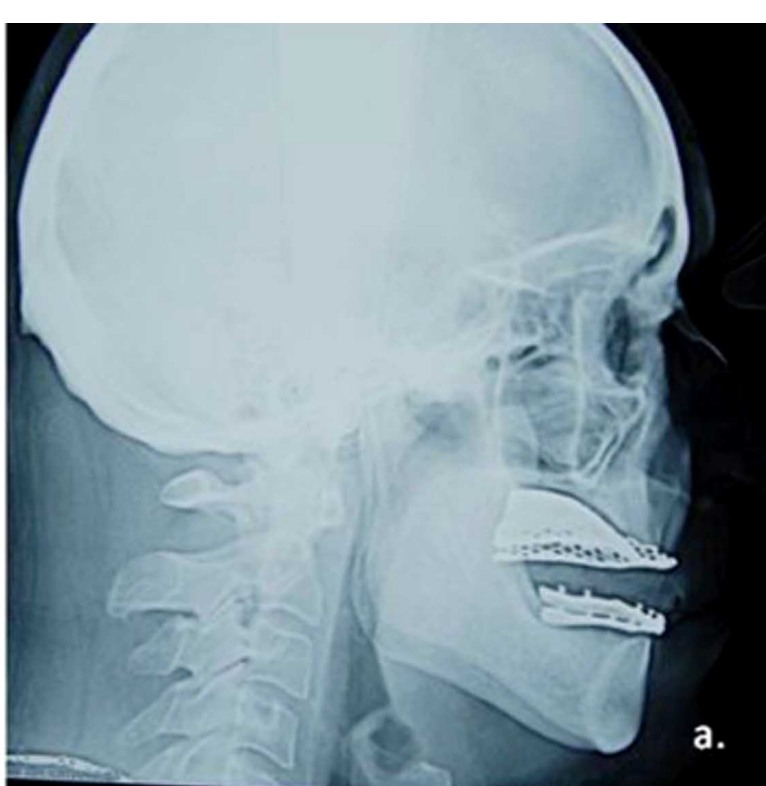
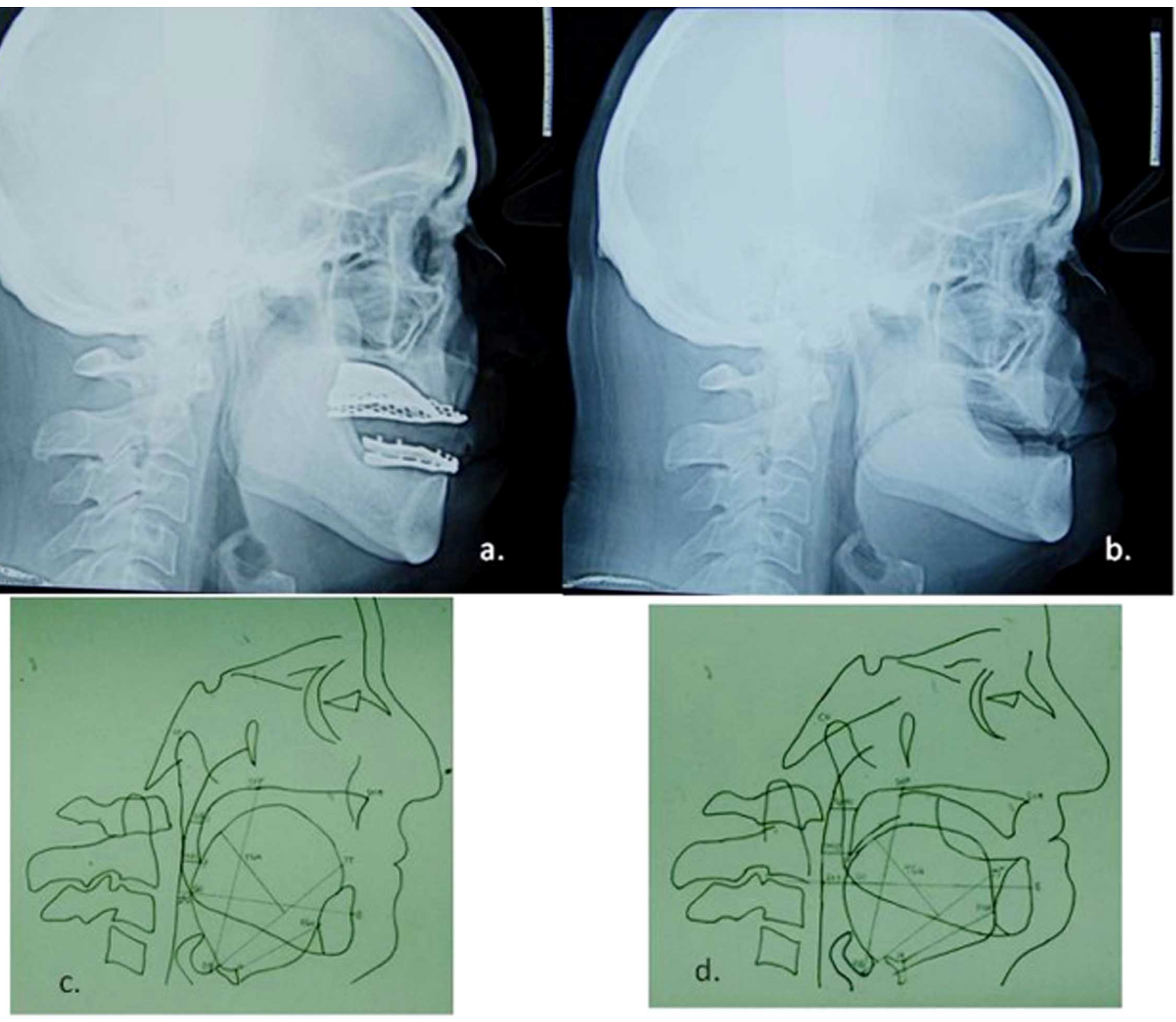

without wearing dentures during the night showed that AHI was reduced from 20.0 per hour to 5.7 per hour and mean $\mathrm{SaO}_{2}$ increased from $94.0 \%$ to $96.0 \%$. Cephalometric analysis showed that the removal of dentures led to a striking increase in the anteroposterior oropharyngeal wall distance: in particular, MAS increased from $6 \mathrm{~mm}$ to $11 \mathrm{~mm}$, PAS from $5 \mathrm{~mm}$ to $10 \mathrm{~mm}$ and IAS from $11 \mathrm{~mm}$ to $15 \mathrm{~mm}$. The mandible plane-hyoid (MP-H) distance did not change and it measures $20 \mathrm{~mm}$. The distance of epiglottis to tongue tip was lower in the radiograph without dentures than with dentures (Eb-TT: $67 \mathrm{~mm}$ with dentures, $61 \mathrm{~mm}$ without dentures), the tongue in radiograph with dentures was more height than in radiograph without dentures (TGH $42 \mathrm{~mm}$ with dentures, 37 without dentures). The distance of Hyoid to retro-gnation was lower with dentures than without dentures (H-RGN 37 $\mathrm{mm}$ with dentures, $40 \mathrm{~mm}$ without dentures).

These findings were consistent with our hypothesis that edentulism not always worse OSA by an oropharyngeal collapse (Fig. 2).

\section{DISCUSSION}

The edentulism is a very common condition in the elderly, with a prevalence ranging between 12.8 and $69.6 \%$ in the population aged over 64 years [23]. 
Table 1. Cephalometric Landmarks

\begin{tabular}{|c|c|}
\hline Sella (S) & Mid point of sella turcica \\
\hline Orbitale (Or) & Most inferior anterior point on margin of orbit \\
\hline Porion $(\mathrm{Po})$ & Upper most point on bony external auditory meatus \\
\hline Posterior Nasal Spine (PNS) & The tip of the posterior spine of the palatine bone in the hard palate \\
\hline Gonion (Go) & The most lateral external point at the junction of the horizontal and ascending ramus of the mandible \\
\hline Menton (Me) & The lowest point on the body outline of the mandible symphysis. \\
\hline maxilla point $\mathrm{A}$ & deepest midline point on the maxillary alveolus between ANS and the maxillary alveolar crest \\
\hline Pogonion (PG) & The most anterior part of mandubular symphysis \\
\hline Hyoidale $(\mathrm{H})$ & the most superior-anterior point on the hyoid bone. \\
\hline Articulare (AR) & The cephalometric junction between clivus and ascending ramus of mandible \\
\hline
\end{tabular}

There are a multitude of risk factors that may impact the onset as well as the progression of an obstructive sleep apnea, but the edentulism is not still recognized among them. The risk factors frequently associated with OSA are listed in Table 3.

Although sleep disorders may potentially increase the risk for a multitude of health problems, it is not an absolute that a given sleep disorder will lead to any one specific health problem. The important issue is to recognize that these health problems may have an underlying sleep disorder as a contributing factor in the development or progression of a health issue. The more common health conditions associated with sleep disorders are listed in Table 4.

There are also associations of sleep disorders with impairments in performance relative to attention and reaction time, which could have significant impact in occupational settings.

Many authors suggest that denture has a protective role on OSAS onset [24-27]. Its function is to improve a vertical dimension of occlusion (VDO) increase, a correct tongue position, an upper airway collapse reduction and a mandibular advancement.

These findings were evaluate in the present paper. Patient without dentures change upper and lower airway spaces. These modifications were probably due to soft palate and tongue position with dentures. Tongue increases its height to support denture in correct position and at last denture exerts pressure on soft palate narrowing MAS and PAS. Tongue modification related to dentures induced changes of epiglottis posture. Without denture epiglottis increases its distance from the pharynx. This could useful for the correct passage of air to the lower airway.
Dentures design would considered these evidences to reduce risk of air way obstruction. In patients with enlarged tongue dentures may stress soft palate and epiglottis and finally to generate a narrowing of upper, medium and lower airway (Fig. 2).

Normally, dentures are built in acrylic with about two millimeters of thickness [28] and they haven't to cause any change in soft palate position. In the present study a patient with a probably uncorrect dentures was presented.

The dentist now has an ever-increasing role in the recognition of a patient who may be at risk for a sleep disorder, so that the clinical case presented can't be underestimated.

\section{CONCLUSIONS}

Since the patient reported a great relief of symptoms after he stopped to wear dentures at night, it's possible to say that edentulism does not always favor upper airway obstruction during sleep. In fact, AHI was significantly worse in the night slept with dentures than in that without them.

Given the common occurrence of both conditions among the elderly, such as the reduction of obstructive sleep apneas with or without dentures, the observed relationship requires further investigations on the mechanisms through which the loss of teeth could help upper airway collapse during the night. This is required to determine if it is necessary or not for the patient completely edentulous to wear the dentures during the sleep in order to avoid the worsening of obstructive sleep apnea. It is therefore clearly important the role the dentist should take against this population, whereas the regular follow-up and use of simple screening questionnaires for OSA can improve his quality of life. 
Table 2. Polysomnographic and Cephalometric Data with and without Dentures

\begin{tabular}{|c|c|c|c|}
\hline & & PRE (with Dentures) & POST (without Dentures) \\
\hline \multirow{6}{*}{ Respiratory Exam } & HIGH PAS & $6 \mathrm{~mm}$ & $11 \mathrm{~mm}$ \\
\hline & MID PAS & $5 \mathrm{~mm}$ & $10 \mathrm{~mm}$ \\
\hline & LOW PAS & $11 \mathrm{~mm}$ & $15 \mathrm{~mm}$ \\
\hline & AHI & $20,0 / \mathrm{h}$ & $5,7 / \mathrm{h}$ \\
\hline & MEAN $\mathrm{SaO}_{2}$ & $94,0 \%$ & $96,0 \%$ \\
\hline & MP-H & $20 \mathrm{~mm}$ & $20 \mathrm{~mm}$ \\
\hline \multirow{20}{*}{ Scheletric Exam } & SNA & $82,5^{\circ}$ & $83,5^{\circ}$ \\
\hline & SNB & $82^{\circ}$ & $89^{\circ}$ \\
\hline & ANB & $0,5^{\circ}$ & $5,5^{\circ}$ \\
\hline & SNPOG & $82^{\circ}$ & $89^{\circ}$ \\
\hline & $\mathrm{S}$ & $122,5^{\circ}$ & $117^{\circ}$ \\
\hline & $\mathrm{AR}$ & $150^{\circ}$ & $146^{\circ}$ \\
\hline & GO & $119^{\circ}$ & $119^{\circ}$ \\
\hline & GO SUP & $43^{\circ}$ & $49^{\circ}$ \\
\hline & GO INF & $76^{\circ}$ & $70^{\circ}$ \\
\hline & TOT & $391,5^{\circ}$ & $382^{\circ}$ \\
\hline & I & $80^{\circ}$ & $81^{\circ}$ \\
\hline & PP PM & $20^{\circ}$ & $12^{\circ}$ \\
\hline & GO ME SN & $30^{\circ}$ & $21^{\circ}$ \\
\hline & SN & $64 \mathrm{~mm}$ & $64 \mathrm{~mm}$ \\
\hline & GOME & $66 \mathrm{~mm}$ & $66 \mathrm{~mm}$ \\
\hline & SAR & $34 \mathrm{~mm}$ & $34 \mathrm{~mm}$ \\
\hline & ARGO & $55 \mathrm{~mm}$ & $55 \mathrm{~mm}$ \\
\hline & AFP & $85 \mathrm{~mm}$ & $84 \mathrm{~mm}$ \\
\hline & AFA & $116 \mathrm{~mm}$ & $106 \mathrm{~mm}$ \\
\hline & AFP/AFA $\%$ & $73 \%$ & $79 \%$ \\
\hline
\end{tabular}

\section{Table 3. Common Risk Factors for OSA}

Increase with age

Snoring/gasping during sleep

Associated with larger neck size

Increase with weight

Males greater than females

Airway obstruction - especially tonsils, adenoids, enlarged tongue, elongated soft palate

Hypothyroidism

Coexisting cardiovascular disease or hypertension

Allergy or asthma

Family history
Table 4. Common Health Issues Possibly Associated with a Sleep Disorder

Painful conditions

Headaches

Arthritis

Fibromyalgia

Anxiety or depression

Stress

Hyperthyroidism

Pregnancy

Gastro-esophageal reflux disease

Medications

Cardiovascular disease

Hypertension 


\section{ACKNOWLEDGEMENT}

None declared.

\section{CONFLICT OF INTEREST}

None declared.

\section{REFERENCES}

[1] Young T, Palta M, Dempsey J, Skatrud J, Weber S, Badr S. The occurrence of sleep-disordered breathing among middle-aged adults. N Engl J Med 1993; 328(17): 1230-5.

[2] Ciavarella D, Sabatucci A, Mastrovincenzo M, et al. Obstructive sleep apnea treatment with a new oral appliance: somnodent. Open Otorhinolaryngol J 2009; 3: 34-8.

[3] Ten B, Parlevliet KJ, Raasveld MH, Buysmann S, Bemelman FJ, Schellekens PT. Guidelines for the optimal use of muromonab CD3 in transplantation. BioDrugs 1999; 11(4): 277-84.

[4] Bazan-Socha S, Miszalski-Jamka T, Petkow-Dimitrow P, Musial J. Clinical stability of Fabry disease in 54 months' enzyme replacement therapy--follow-up of the first Polish study. Pol Arch Med Wewn 2007; 117(5-6): 260-5.

[5] Margalit N, Ezer H, Fliss DM, Naftaliev E, Nosek E, Kesler A. Orbital tumors treated using transcranial approaches: surgical technique and neuroophthalmogical results in 41 patients. Neurosurg Focus 2007; 23(5): E11.

[6] Bruni O, Russo PM, Ferri R, Novelli L, Galli F, Guidetti V. Relationships between headache and sleep in a non-clinical population of children and adolescents. Sleep Med 2007; 9(5): 5428.

[7] Goldberg AN, Schwab RJ. Identifying the patient with sleep apnea: upper airway assessment and physical examination. Otolaryngol Clin North Am 1998; 31(6): 919-30.

[8] Bliwise DL, Feldman DE, Bliwise NG, et al. Risk factors for sleep disordered breathing in heterogeneous geriatric populations. J Am Geriatr Soc 1987; 35(2): 132-41.

[9] Tishler PV, Larkin EK, Schluchter MD, Redline S. Incidence of sleep-disordered breathing in an urban adult population: the relative importance of risk factors in the development of sleep-disordered breathing. JAMA 2003; 289(17): 2230-7.

[10] Redline S, Kump K, Tishler PV, Browner I, Ferrette V. Gender differences in sleep disordered breathing in a community-based sample. Am J Respir Crit Care Med 1994; 149(3 Pt 1): 722-6.

[11] Liistro G, Rombaux P, Belge C, Dury M, Aubert G, Rodenstein DO. High Mallampati score and nasal obstruction are associated risk factors for obstructive sleep apnoea. Eur Respir J 2003; 21(2): 248-52.

[12] Jamieson A, Guilleminault C, Partinen M, Quera-Salva MA. Obstructive sleep apneic patients have craniomandibular abnormalities. Sleep 1986; 9(4): 469-77.
[13] Bixler EO, Vgontzas AN, Ten Have T, Tyson K, Kales A. Effects of age on sleep apnea in men: I. Prevalence and severity. Am J Respir Crit Care Med 1998; 157(1): 144-8.

[14] Paoli JR, Lauwers F, Lacassagne L, Tiberge M, Dodart L, Boutault F. Craniofacial differences according to the body mass index of patients with obstructive sleep apnoea syndrome: cephalometric study in 85 patients. Br J Oral Maxillofac Surg 2001; 39(1): 40-5.

[15] Otsuka R, Ono T, Ishiwata Y, Kuroda T. Respiratory-related genioglossus electromyographic activity in response to head rotation and changes in body position. Angle Orthod 2000; 70(1): 63-9.

[16] Hagiwara N, Kamouchi M, Inoue T, Ibayashi S, Iida M, Okada Y. Dissection of bilateral intracranial vertebral artery with basilar artery involvement: a case report of a patient free from neurological deficits. Intern Med 2007; 46(17): 1467-70.

[17] Collop NA, Anderson WM, Boehlecke B, et al. Clinical guidelines for the use of unattended portable monitors in the diagnosis of obstructive sleep apnea in adult patients. Portable Monitoring Task Force of the American Academy of Sleep Medicine. J Clin Sleep Med 2007; 3(7): 737-47.

[18] Johns MW. A new method for measuring daytime sleepiness: the Epworth sleepiness scale. Sleep 1991; 14(6): 540-5.

[19] Johns M, Hocking B. Daytime sleepiness and sleep habits of Australian workers. Sleep 1997; 20(10): 844-9.

[20] Parkes JD, Chen SY, Clift SJ, Dahlitz MJ, Dunn G. The clinical diagnosis of the narcoleptic syndrome. J Sleep Res 1998; 7(1): 4152.

[21] Tietjen GE, Bushnell CD, Herial NA, Utley C, White L, Hafeez F. Endometriosis is associated with prevalence of comorbid conditions in migraine. Headache 2007; 47(7): 1069-78.

[22] Nuckton TJ, Glidden DV, Browner WS, Claman DM. Physical examination: Mallampati score as an independent predictor of obstructive sleep apnea. Sleep 2006; 29(7): 903-8.

[23] Guigoz Y, Vellas B, Garry PJ. Assessing the nutritional status of the elderly: The Mini Nutritional Assessment as part of the geriatric evaluation. Nutr Rev 1996; 54(1 Pt 2): S59-65.

[24] Bucca C, Carossa S, Pivetti S, Gai V, Rolla G, Preti G. Edentulism and worsening of obstructive sleep apnoea. Lancet 1999; 353(9147): 121-2.

[25] Bucca C, Cicolin A, Brussino L, et al. Tooth loss and obstructive sleep apnoea. Respir Res 2006; $7: 8$.

[26] Ancoli-Israel S, Kripke DF, Klauber MR, Mason WJ, Fell R, Kaplan O. Sleep-disordered breathing in community-dwelling elderly. Sleep 1991; 14(6): 486-95.

[27] Meyer JB Jr, Knudson RC. Fabrication of a prosthesis to prevent sleep apnea in edentulous patients. J Prosthet Dent 1990; 63(4): 448-51.

[28] Schierano G, Mozzati M, Bassi F, Preti G. Influence of the thickness of the resin palatal vault on the closest speaking space with complete dentures. J Oral Rehabil 2001; 28(10): 903-8. 